\title{
How are hospitals using artificial intelligence in strategic decision- making? - a scoping review
}

\author{
Sandra G. Leggat^, Kevin Yap \\ Department of Public Health, La Trobe University, Bundoora, Australia \\ Contributions: (I) Conception and design: All authors; (II) Administrative support: SG Leggat; (III) Provision of study materials or patients: SG \\ Leggat; (IV) Collection and assembly of data: SG Leggat; (V) Data analysis and interpretation: All authors; (VI) Manuscript writing: All authors; (VII) \\ Final approval of manuscript: All authors. \\ Correspondence to: Sandra G. Leggat. Department of Public Health, La Trobe University, Bundoora 3086, Australia. Email: s.leggat@latrobe.edu.au.
}

\begin{abstract}
Artificial intelligence (AI) is a useful tool for clinical decision-making in hospitals, and for strategic decision-making in other industries. This scoping review provides a comprehensive review of the potential for AI to improve strategic decision-making in hospitals by exploring current applications of AI in this area. Peer-reviewed publications and conference presentations associated with AI for strategic decisionmaking were identified in Health Administration, Computer Science and Business and Management databases to answer the research question; how are hospitals using AI in strategic decision-making? The review found 19 published AI applications for hospital strategic decision-making. The applications used a variety of knowledge-based, probabilistic reasoning and data-driven AI, that generally followed the course of AI maturity. They focused on specific decisions, with none providing a comprehensive framework for strategic decision-making drawing on existing enterprise- or system-wide data. There was little evidence of evaluation of the AI applications, with no cost-benefit evaluation. The scoping review suggests the need for substantial improvement in the understanding of AI and its application among hospital decisionmakers leading to greater organisational maturity. This would suggest that journals and researchers require evaluative and economic research and that training to improve understanding of AI be provided for board members, managers and clinicians.
\end{abstract}

Keywords: Artificial intelligence (AI); hospitals; strategic decision-making; decision support systems

Received: 22 June 2020. Accepted: 20 November 2020; Published: 25 December 2020.

doi: 10.21037/jhmhp-20-92

View this article at: http://dx.doi.org/10.21037/jhmhp-20-92

\section{Introduction}

Artificial intelligence (AI) is defined as "a system's ability to correctly interpret external data, to learn from such data, and to use those learnings to achieve specific goals and tasks through flexible adaptation" (1). That is, AI is useful for analysing the ever growing accumulated data and taking action based on what is learned from the data (2). Developments in automation have enabled progression from relatively simple rules-based decision support to supervised and unsupervised machine learning (3). As a result, there are many aspects of
$\mathrm{AI}$, some currently in use and others only imagined in future scenarios. The terminology is both complex and evolving, with terms such as machine learning, deep learning, artificial neural networks (ANNs), fuzzy models, pattern recognition and computer prediction represented in the literature, and falling in and out of fashion over time $(4,5)$.

Authors have tracked increasing use of AI in health services and systems. For example, while a pre-1995 literature review found no published decision support applications in healthcare, this increased to $2 \%$ of 210

^ ORCID: 0000-0002-2252-4302. 
identified healthcare applications between 1995 and 2001 (6). The greatest use of AI in healthcare is support for clinical decisions, such as diagnosis (7), including interpretation of medical images (8), and treatment planning $(2,9)$. Recent literature reviews have documented increasing support for the use of AI in these clinical applications. For example, there is evidence that ANNs can diagnose medical conditions in patients more accurately than clinicians (7).

In recent years, with the advent of large datasets (big data) and increasing computing power, AI has been identified as the most important strategic business technology (10), and is being used more frequently (11). Despite the identified benefits of $\mathrm{AI}$ in both clinical and business applications, there has been limited application to management decisionmaking in healthcare. A 2018 systematic literature review found that only $7 \%$ of the 75 included articles described AI for system management (2). A 2019 scoping review found that only 10 of 80 articles (12.5\%) presented the use of ANNs at the organisational decision level (9). The majority of the ANN applications were clinical, such as diagnosis of heart conditions, prediction of diabetes based on risk factors and evaluating patient wounds.

Strategic decision-making is the process underlying the development and implementation of organisational strategies. Strategic decision-making is a key component of strategic planning and management (12). Strategic decision-making has been defined as "a non-routine decision process that has long term consequences" (13). Previous authors have suggested that it has been difficult to incorporate $\mathrm{AI}$ into strategic planning in most industries (14). The reasons given are that strategic planning is a complex organisational communication and negotiation process that makes use of AI difficult $(13,15)$. Specifically, the strategic planning process is influenced by culture, where strategies are shaped by group norms and practices (16). In addition, organisational executives consider strategic planning an art, not requiring computerbased decision support of any kind $(13,14,17)$. Perhaps most importantly, there is no single 'correct' strategic answer, and it takes years before the success of the strategic decisions can be evaluated (14). In the business literature, only $6 \%$ of 271 identified computer decision support applications were used for strategic management (18), and this reduced to approximately $3 \%$ of 210 applications in a follow up literature review published in 2006 (6).

It has been suggested that AI can be used for strategic decision support in areas such as analysing external environment and industry trends (19), evaluating mergers and acquisitions, exploring market position and portfolios, and planning multi-level (corporate, division, department) and multifunctional operations, selecting and evaluating strategy (20) and managing organisational crises (21). In addition, AI has been found to be effective at identifying and analysing risk, as it is not bound by human biases and emotions (16). As an example, Ladeira and Linhares showed how fuzzy logic AI could be used by three businesses in Brazil to populate strategies in their organisational strategic balanced scorecard (22). The importance of AI in strategic decision-making increases as organisations and industries become more complex, ensuring that essential strategic information is not overlooked (13).

In fact, strategic decision-making in healthcare seems like an ideal environment for AI. First, it has been shown that humans, even those with domain-specific expertise, are extremely poor in predicting future events in complex social systems (23). Second, as described above the strategic planning process involves the use of biased data, in terms of what has been collected and what is considered in the decision-making process $(16,24)$. These biased data are then subjectively analysed by a group of humans (16). Finally, appropriate stewardship of the public money invested in health care services would suggest the need for effective decision support when resulting decisions may impact life and death.

We present the following article in accordance with the Narrative Review reporting checklist (available at http:// dx.doi.org/10.21037/jhmhp-20-92).

\section{Rationale for a scoping review}

There is evidence that hospitals and other health service organisations have difficulty in strategic planning and management (24-26). Given that AI has been shown to enhance clinical decision-making, AI may also assist strategic decision-making within hospitals. The overarching goal of this scoping review is to provide a comprehensive review of the potential for AI to improve strategic decisionmaking in hospitals by exploring current applications of AI in this area. This review will enable identification of the nature and extent of relevant literature and describe the context of AI methodologies used.

\section{Methods}

\section{Search strategy}

The search strategy was designed to identify literature 


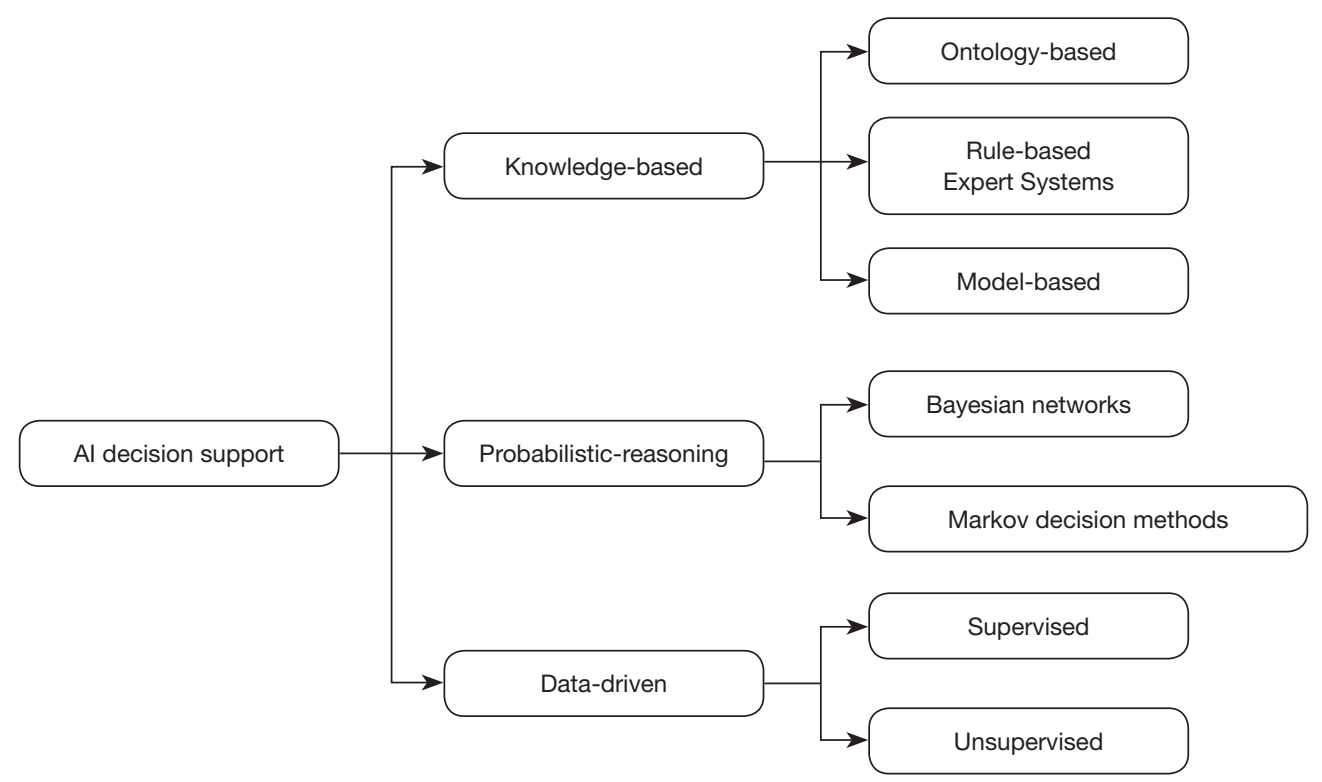

Figure 1 Options for AI decision-making. AI, artificial intelligence.

from multiple databases to include the disciplines of Health Administration (Medline and Embase), Computer Science (ACM Digital Library and Advanced Technologies \& Aerospace Database), and Business and Management (ABI/ Inform Global and JSTOR). These three disciplines reflect the core concepts embedded in our research question: How are hospitals using AI in strategic decision-making? All peer-reviewed articles were included whether they were published in journals, books or conference proceedings. Non peer-reviewed articles were not included.

Figure 1 outlines the options for AI decision-making that are covered in the review, and which led to the search terms outlined below.

Search terms included: AI, and specific AI components of machine learning, ANNs, dimensionality reduction, deep learning, reinforcement learning, pattern recognition, prediction/classification, clustering, Markov decision methods, natural language processing, fuzzy systems/ models, multi-agent systems and computational intelligence/prediction, combined with strategy, strategic decision-making, strategic planning and strategic management, and hospital or healthcare or health service organisation.

\section{Data collection}

Titles and abstracts were screened, with no limits imposed on date of publication. The inclusion criteria included articles with keywords related to the search terms outlined above or with explicit reference to AI. Articles focused on the development of electronic medical or health records specifically were not included. If the application was not in the context of health care strategic organisational decision-making, such as operations management, including scheduling and patient dependency applications, it was excluded. Subsequently, a full-text review of articles that met the initial screening criteria was conducted to confirm the availability and the relevance of the information in the article for data extraction.

\section{Results}

Figure 2 outlines the papers identified for inclusion in the review.

Table S1 outlines the AI applications described in the literature for use in strategic decision-making in hospitals. The papers were found in a variety of journals, comprising healthcare management, medical informatics, and information systems and decision support.

There were four literature reviews that were either focused on AI in healthcare or which included healthcare as one of the industries discussed within a broader AI literature review. While many of the reviews suggested that expert or knowledge-based systems were used most frequently, our review found more data-driven AI applications. This is expected, as it is difficult to assign rules to strategic 


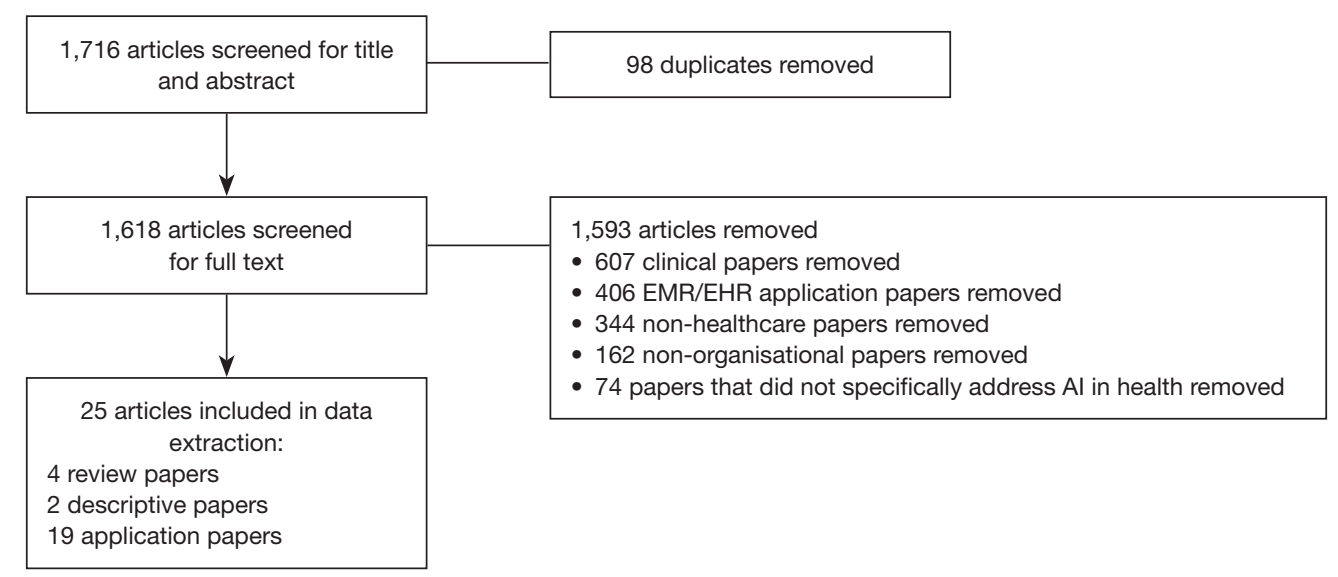

Figure 2 Identified documents. AI, artificial intelligence.

decision-making suggesting data-driven AI is more appropriate for strategic decision-making (16). The reviews focused on AI in general $(5,6), \mathrm{ANN}(9)$, and accounting for uncertainty (27) in healthcare decision-making. Uncertainly is described further below.

While multi-criteria decision analysis was identified as a particularly useful technique for strategic and policy decisions in healthcare, it was suggested that dealing with uncertainly was problematic (27). This led to the review which recommended deterministic sensitivity analysis to deal with uncertainty when the criteria weights were varied as a single value, and the gray approach as most appropriate if only lower and upper bounds were used. However, important to strategic decision-making, which is usually a group decision process, the requirement to combine the opinions of several decision-makers made probabilistic sensitivity analysis and fuzzy set approaches most appropriate (27).

Two descriptive studies were included in the data extraction; covering senior manager opinions of AI applicability to their hospitals in Sweden (13) and case studies exploring the adoption of wireless vital sign monitoring technology in two Asian hospitals (28). The second study focused on the identification of enabling factors, and while the application was solely clinical, similar enabling factors may influence the use of AI technology in strategic decisionmaking. The surveyed senior managers indicated that current systems were too complex and lacked the trust of the managers. They suggested that it would not be possible to use ICT to a greater extent in strategic decision-making without simplification and standardisation of the applications (13). Although limited by the small sample of only two case studies, Yang et al. suggested that implementation of AI would be more successful in hospitals if the application focused on addressing a clinical issue and was supported through redirection of organisational resources that demonstrated an organisation-wide mandate (28).

There were 19 papers that described AI applications that were used or could be used for strategic decision-making in hospitals. Unfortunately, in relation to the quality of the studies, few of the applications were evaluated, with only seven papers (36\%) including evidence of evaluation. Consistent with commentary by other authors (3), AI was presented as a viable tool, with little attention paid to potential bias. The applications identified in the literature are described in relation to knowledge-based, probabilistic reasoning or data-driven types of applications below (as outlined in Figure 1).

\section{Knowledge-based}

There were seven knowledge-based applications for strategic decision-making identified, with most constructed using a rules-based design. In the late 1990s applications aimed to gather information from existing healthcare databases to assist in identifying and choosing future strategies (29-31). While in most cases there was no evaluation, the Hospital Management Support System (HMSS) was evaluated comparing the performance of a control and experimental group of students and health professionals on planning tasks using a standard decision support system and the HMSS (29). The evaluation suggested the HMSS enabled greater maturity in decision-making, but only in the gathering intelligence and implementation confidence in the decision 
phases. There was little impact on the other decision phases, comprising design or choice of processes phases (29).

Around the same time Moreno and colleagues developed a computer simulation to track patient flow resulting from simulated strategic decisions (32) and then incorporated the simulation into a knowledge-based system for hospital management decision-making (33). Although the authors suggested that the collaboration between simulation and AI was a valuable technique in the analysis of complex systems there was no reported evaluation (33). Edmonds and O'Conner also developed discrete-event stochastic computer simulation using MS Access to model various strategies for hospital restructuring in Canada (34). Three scenarios were completed, but there was no evaluation of the accuracy of the simulation results. Finally, the ServiceOriented Multi-Agent Systems (SOMAS) was a knowledgebased application using organisational information including roles of agents and the interactions among these agents in the provision of services to model service coordination (35). SOMAS was found to provide service matching more effectively and efficiently than human processing. Fala and colleagues (36) described four expert systems that they suggested were useful for health services management in the USA, comprising INFER, PsychINFER, Procedure Necessity, and Alternatives to Non-Surgical Admissions. Each of these were developed using knowledge engineering, and the authors claimed they were cost-effective, but evaluation results were not reported. One additional knowledge-based system, constructed by Mousakhani $e t$ al. with a model-based approach, incorporating fuzzy logic, was used to rank the achievement of the strategic objectives of five Iranian hospitals (37). There was no evaluation of this application.

\section{Probabilistic reasoning}

A Bayesian Network was constructed to track resource utilisation and identify strategies to improve efficiency using radiology data in a private hospital in Turkey (38). The authors illustrated how the decision support model could be used to improve strategic decision-making but did not evaluate the application. In a Chinese hospital a probabilistic model using natural language processing was found to be effective at designing treatment plans (39). However, the authors identified many barriers to the adoption of this technology, including reluctance to share data among hospitals and lack of trust of AI by health professionals. McClean and Millard outlined a Markov analysis that costed treatment options, including acute care, residential and nursing home, for older adults (40). The results suggested it was more cost-effective to retain older adults in acute care to improve their functioning, when compared to transfer to a less intensive level of care, however there was no evaluation as the authors suggested accurate data were difficult to obtain. Finally, a Markov decision process using patient demand, treatment patterns and hospital resources was developed to plan elective hospital utilisation by specialty, but again without evaluation (41).

\section{Data-driven}

Erdoğan and colleagues described a spreadsheet-based algorithm that accessed geographic information system data that the authors used to plan maternity service sites for a UK hospital network. Although the recommendations from the application were accepted and implemented, there was no evaluation provided (42). From 2011 on, there was a greater focus on application of ANNs. A 2019 scoping review found the majority of the ANN published applications were related to clinical decision-making, with only six applications that might have been related to organisational strategic decision-making (9). Further analysis of these six articles found that two of the predictive models, the first predicting health status using Indonesian population health indicators such as birth rate, infant mortality rate and morbidity from tuberculosis (43), and the second predicting revenue generation by USA hospital foundations using SPSS Clementine type nodes (44) were useful for strategic decision-making. Both of these applications were evaluated against existing common practice. The predicted values were found to be close to the actual values in the Indonesian population health model and the hospital foundation ANN outperformed multiple regression analysis. The remaining four studies were focused on clinical decisions $(45,46)$ or management of operations, such as adoption of radio frequency identification (RFID) technology adoption in a clinical setting (47) and evaluating the effect of hospital employee motivation on patient satisfaction (48).

The current review found three additional ANN applications for strategic decision-making that had not been included in the scoping review. Two applications were focused on analysis of text-based clinical data to address patient harm, and the ANNs were found to outperform human analysis of the same data $(49,50)$. Another application used ANNs to predict hospital readmissions and was found to perform better than existing practice (51). 


\section{Discussion}

Our scoping review suggests that AI applications for hospital strategic decision-making closely mirrored the general development of AI. Early decision support for both strategy and operations was focused on knowledge-based systems $(30,33)$, which were further augmented with rulesbased systems (36). However, various authors have outlined the limitations of rules-based developments in capturing the contexts important for planning (52), and the complex nature of strategic knowledge (14). Model-based (37) and expert analytical systems (32) were developed to overcome these weaknesses. From 2011 the published applications drew upon deep learning most often obtained through ANN AI technology $(43,44,49)$.

There were no applications found in the literature that provided a comprehensive sustainable framework for strategic decision-making drawing on existing enterprisewide data. As identified by other authors, the focus has been on specialised local applications focused on a particular aspect of organisational decision-making (53). In addition, there were no AI applications found which used the large amounts of data health by various organisations within the system to inform both system-wide and local strategic planning and coordination. A systematic review of blockchain in healthcare suggested that blockchain could be an important technology for managing interorganisational data to facilitate AI (54). Cross-organisational planning and management is hampered by issues related to confidentiality and privacy of the data and therefore has not reached required interoperability. The examples of crossorganisational data management found in the blockchain literature, suggests opportunities for use of data related to population health that are held by many organisations could be an effective resource for AI use in strategic decisionmaking (55).

As early as the 1980s six roles were identified for knowledge-based systems: assistant, critic, second opinion, expert, consultant, tutor, and automation (56). Our review suggests that AI which conforms to any of these roles, except automation, is more likely to be preferred and accepted by human strategists (16). This is consistent with the suggestion that AI strategic decision support should target the 'intelligence' and 'design' phases, rather than the 'choice' phase, of the three-phase strategic planning process (57). This further suggests that understanding how the analysis is completed is important for strategic decisionmaking in hospitals. Clinicians, in particular, are unlikely to adopt a system they cannot understand, and while the more advanced AI models seem to perform well, making them more understandable is important for trustable and reliable systems $(13,58)$. As predicted by socio-technical theory $(59,60)$, the challenges to AI implementation are rarely technical (39), but have more to do with the social aspects of change. The most common barrier found in this scoping review was social in that if hospital managers and clinicians did not understand how the application worked and did not trust the analysis they would be unlikely to adopt AI (13). This suggests the need for training to increase understanding and use of AI among hospital board members, managers and clinicians.

Consistent with our increasing understanding of the acceptance of new technology in healthcare, the level of maturity of the organisation may be related to the adoption of AI (61). For example, Grossman defined five levels of organisational maturity in analytical processes: 1 , the organization can build reports; 2 , the organization can build and deploy models; 3 , the organization has repeatable processes for building and deploying analytics; 4 , the organization has consistent enterprise-wide processes for analytics; and 5 , the enterprise's analytics is strategy driven (62).

Our scoping review suggests that few hospitals can demonstrate levels of organisational maturity in analytical processes beyond level 2. There was little evidence of repeatable analytical processes presented in the literature and even less for consistent enterprise-wide processes within hospitals (53). This would severely limit the ability of hospitals to implement strategy driven analytics.

While 19 applications of AI for hospitals' strategic decision-making were identified, the more recent ANN applications were more likely to be evaluated. In many of the papers, particularly in the technical journals, the focus was on describing the AI application, with less attention paid to the context and impact of the application. When there were evaluations presented, they compared the new analytical approach to existing methods $(44,49,51)$, or in one case, to human data extraction (50). There were no cost-benefit evaluations found. As a result, the AI literature suggests incremental improvements, incorporating the recommended probabilistic and fuzzy logic AI to effectively deal with uncertainty (27), but has not yet demonstrated the overall value of AI to strategic decision-making in hospitals. Our findings suggest that future research should focus on the use of existing big data to improve strategic capabilities of $\mathrm{AI}$ in healthcare, as well as more robust evaluation of $\mathrm{AI}$ 
applications.

\section{Conclusions}

While this scoping review identified AI applications for use in strategic decision-making in hospitals, our findings also suggest the need for substantial improvement in the understanding of AI and its application among hospital decision-makers leading to greater organisational maturity. The limited organisational maturity, with lack of repeatable processes for developing, using and evaluating AI limits the effectiveness of AI for strategic decision-making. Most of the applications found in the literature did not provide a comprehensive sustainable framework for strategic decision-making drawing on existing enterprise-wide data but focused on selected aspects of organisation decisionmaking. The lack of understanding and support for AI among hospital decision-makers may be associated with the general lack of evaluation, particularly cost-benefit analysis, of the AI applications. Our scoping review suggests the need for both focused evaluation and economic research and training in increasing understanding of AI.

\section{Acknowledgments}

Funding: None.

\section{Footnote}

Provenance and Peer Review: This article was commissioned by the Guest Editors (Sandeep Reddy, Jenifer Sunrise Winter, and Sandosh Padmanabhan) for the series "AI in Healthcare - Opportunities and Challenges" published in Journal of Hospital Management and Health Policy. The article has undergone external peer review.

Reporting Checklist: The authors have completed the Narrative Review reporting checklist. Available at http:// dx.doi.org/10.21037/jhmhp-20-92

Conflicts of Interest: Both authors have completed the ICMJE uniform disclosure form (available at http://dx.doi. org/10.21037/jhmhp-20-92). The series "AI in Healthcare Opportunities and Challenges" was commissioned by the editorial office without any funding or sponsorship. The authors have no other conflicts of interest to declare.

Ethical Statement: The authors are accountable for all aspects of the work in ensuring that questions related to the accuracy or integrity of any part of the work are appropriately investigated and resolved.

Open Access Statement: This is an Open Access article distributed in accordance with the Creative Commons Attribution-NonCommercial-NoDerivs 4.0 International License (CC BY-NC-ND 4.0), which permits the noncommercial replication and distribution of the article with the strict proviso that no changes or edits are made and the original work is properly cited (including links to both the formal publication through the relevant DOI and the license). See: https://creativecommons.org/licenses/by-nc-nd/4.0/.

\section{References}

1. Kaplan A, Haenlein M. Siri, Siri, in my hand: who's the fairest in the land? On the interpretations, illustrations, and implications of artificial intelligence. Bus Horiz 2019;62:15-25.

2. Shah R, Chircu A. IOT and AI in healthcare: a systematic literature review. Issues in Information Systems 2018;19:33-41.

3. Challen R, Denny J, Pitt M, et al. Artificial intelligence, bias and clinical safety. BMJ Qual Saf 2019;28:231-7.

4. Kononenko I. Machine learning for medical diagnosis: history, state of the art and perspective. Artif Intell Med 2001;23:89-109.

5. Duan Y, Edwards JS, Dwivedi YK. Artificial intelligence for decision making in the era of Big Data-evolution, challenges and research agenda. Int J Inf Manage 2019;48:63-71.

6. Eom S, Kim E. A survey of decision support system applications (1995-2001). J Oper Res Soc 2006;57:1264-78.

7. Amato F, López A, Peña-Méndez EM, et al. Artificial neural networks in medical diagnosis. Journal for Applied Biomedicine 2013;11:47-58.

8. Wang YH, Lin GY. Exploring smart healthcare innovations: multiple patentometric analyses. In: Proceedings of the 2020 the 3 rd International Conference on Computers in Management and Business, 2020:117-20.

9. Shahid N, Rappon T, Berta W. Applications of artificial neural networks in health care organizational decisionmaking: a scoping review. PLoS One 2019;14:e0212356.

10. Panetta K. Gartner top 10 strategic technology trends for 2018. Retrieved Gartner Group 2018.

11. Bean R. How big data and AI are driving business innovation in 2018. MIT Sloan Management Review 2018. 
12. George B, Desmidt S, De Moyer J. Strategic decision quality in Flemish municipalities. Public Money \& Management 2016;36:317-24.

13. Hedelin L, Allwood CM. IT and strategic decision making. Industrial Management \& Data Systems 2002;102:125-39.

14. Spangler WE. The role of artificial intelligence in understanding the strategic decision-making process. IEEE Trans Knowl Data Eng 1991;3:149-59.

15. Dutton LE, Fahey L, Narayanan VK. Toward understanding strategic issue diagnosis. Strategic Management Journal 1983;4:307-23.

16. Ayoub K, Payne K. Strategy in the age of artificial intelligence. Journal of Strategic Studies 2016;39:793-819.

17. Young L. A systems architecture for supporting senior management's messy tasks. Information Management 1987;13:85-94.

18. Eom SB, Lee SM, Kim EB, et al. A survey of decision support system applications (1988-1994). J Oper Res Soc 1998;49:109-20.

19. Barnikow A, Behrendt U, Hartmann K, et al. DICTUM: Decision support system for analysis and synthesis of large-scale industrial systems-part 1: components. Comput Ind 1992;18:135-53.

20. Tavana M, Banerjee S. Strategic assessment model (SAM): a multiple criteria decision support system for evaluation of strategic alternatives. Decision Science 1995;26:119-43.

21. Nunamaker JFJ, Weber ES, Chen M. Organisational crisis management systems: Planning for intelligent action. J Manag Inf Syst 1989;5:7-32.

22. Ladeira M, Linhares F. A Verbal Anchor based Fuzzy System to help business managers build Balanced Scorecards Strategy Maps. In: Anais Principais do XI Simpósio Brasileiro de Sistemas de Informação. Goiania: Brazilian Computer Society, 2015:549-54.

23. Tetlock PE. Expert political judgment: how good is it? How can we know? Princeton: Princeton University Press, 2005.

24. Zuckerman AM. Advancing the state of the art in healthcare strategic planning. Front Health Serv Manage 2006;23:3-15.

25. Leggat SG. Hospital planning: the risks of basing the future on past data. Health Inf Manag 2008;37:6-14.

26. Leggat SG. Strategic planning. In: Day GE, Leggat SG. editors. Leading and managing health services: an Australasian perspective. Melbourne: Cambridge University Press, 2015.

27. Broekhuizen H, Groothuis-Oudshoorn CG, van Til JA, et al. A review and classification of approaches for dealing with uncertainty in multi-criteria decision analysis for healthcare decisions. Pharmacoeconomics 2015;33:445-55.

28. Yang Z, Kankanhalli A, Ng B, et al. Analyzing the enabling factors for the organizational decision to adopt healthcare information systems. Decision Support Systems 2013;55:764-76.

29. Forgionne GA, Kohli R. HMSS: a management support system for concurrent hospital decision making. Decision Support Systems 1996;16:209-29.

30. Abidi SSR. Applying data mining in healthcare: An infostructure for delivering "data-driven" strategic services. In: Kokol P, Zupan B, Stare J, et al. editors. Medical informatics in Europe. Amsterdam: IOS Press, 1999:453-6.

31. Ramani KV. A management information system to plan and monitor the delivery of health-care services in government hospitals in India. J Health Organ Manag 2004;18:207-20.

32. Moreno L, Aguilar RM, Martin CA, et al. Patient-centered simulation to aid decision-making in hospital management. Simulation 2000;74:290-304.

33. Moreno L, Aguilar RM, Piñeiro JD, et al. Using KADS methodology in a simulation assisted knowledge based system: application to hospital management. Expert Syst Appl 2001;20:235-49.

34. Edmonds MI, O'Connor HM. The use of computer simulation as a strategic decision-making tool: a case study of an emergency department application. Healthcare Management Forum 1999;12:32-8.

35. Fernández A, Ossowski S. Exploiting organisational information for service coordination in multiagent systems. AAMAS 2008.

36. Fala GJ, Clayton KT, Masciantonio DM. Applying expert systems to health care management. In: Proceedings of the 1995 ACM Symposium on Applied Computing, 1995:237-41.

37. Mousakhani M, Rahmani H, Hamidi N. Hospitals ranking using fuzzy analytic hierarchy process balanced score card. Asian Journal of Management Research 2010;1:666-78.

38. Aktaş E, Ülengin F, Şahin ŞÖ. A decision support system to improve the efficiency of resource allocation in healthcare management. Socio-Economic Planning Sciences 2007;41:130-46.

39. Sun TQ, Medaglia R. Mapping the challenges of Artificial Intelligence in the public sector: Evidence from public healthcare. Gov Inf Q 2019;36:368-83.

40. McClean S, Millard P. Where to treat the older patient? Can Markov models help us better understand the relationship between hospital and community care? J Oper Res Soc 2007;58:255-61. 
41. Nunes LGN, de Carvalho SV, Rodrigues RDCM. Markov decision process applied to the control of hospital elective admissions. Artif Intell Med 2009;47:159-71.

42. Erdoğan G, Stylianou N, Vasilakis C. An open source decision support system for facility location analysis. Decision Support Systems 2019;125:113116.

43. Eswaran C, Logeswaran R. A dual hybrid forecasting model for support of decision making in healthcare management. Adv Eng Softw 2012;53:23-32.

44. Malliaris ME, Pappas M. Revenue generation in hospital foundations: neural network versus regression model recommendations. International Journal of Management \& Information Systems 2011;15:59-66.

45. Atoui H, Telisson D, Fayn J, et al. Ambient intelligence and pervasive architecture designed within the EPIMEDICS personal ECG monitor. Int J Healthc Inf Syst Inform 2008;3:69-80.

46. Berardi VL, Zhang GP. The effect of misclassification costs on neural network classifiers. Decision Sciences 1999;30:659-82.

47. Chong AL, Liu MJ, Luo J, et al. Predicting RFID adoption in healthcare supply chain from the perspectives of users. Int J Prod Econ 2015;159:66-75.

48. Hanafizadeh P, Paydar NR, Aliabadi N. Neural networkbased evaluation of the effect of the motivation of hospital employees on patients' satisfaction. Int J Healthc Inf Syst Inform 2010;5:1-19.

49. Cohan A, Fong A, Ratwani RM, et al. Identifying harm events in clinical care through medical narratives. In: Proceedings of the 8th ACM International Conference on Bioinformatics, Computational Biology, and Health Informatics, 2017:52-9.

50. Tafti AP, Badger J, LaRose E, et al. Adverse drug event discovery using biomedical literature: a big data neural network adventure. JMIR Med Inform 2017;5:e51.

51. Wang H, Cui Z, Chen Y, et al. Predicting hospital readmission via cost-sensitive deep learning. IEEE/ACM

doi: 10.21037/jhmhp-20-92

Cite this article as: Leggat SG, Yap K. How are hospitals using artificial intelligence in strategic decision-making?-a scoping review. J Hosp Manag Health Policy 2020;4:39.
Trans Comput Biol Bioinform 2018;15:1968-78.

52. Dhar V, Pople HE. Rule-based versus structure-based models for explaining and generating expert behavior. Commun ACM 1987;30:542-55.

53. Tjora AH, Scambler G. Square pegs in round holes: information systems, hospitals and the significance of contextual awareness. Soc Sci Med 2009;68:519-25.

54. Agbo CC, Mahmoud QH, Eklund JM. Blockchain technology in healthcare: a systematic review. Healthcare (Basel) 2019;7:56.

55. Casino F, Dasaklis TK, Patsakis C. A systematic literature review of blockchain-based applications: current status, classification and open issues. Telematics and Informatics 2019;36:55-81.

56. Bader J, Edwards J, Harris-Jones C, et al. Practical engineering of knowledge-based systems. Inf Softw Technol 1988;30:266-77.

57. Simon HA. The new science of management decision. New York: Harper and Brothers, 1960.

58. Miotto R, Wang F, Wang S, et al. Deep learning for healthcare: review, opportunities and challenges. Brief Bioinform 2018;19:1236-46.

59. Westbrook JI, Braithwaite J, Georgiou A, et al. Multimethod evaluation of information and communication technologies in health in the context of wicked problems and sociotechnical theory. J Am Med Inform Assoc 2007;14:746-55.

60. Leggat SG, Balding C. A qualitative study on the implementation of quality systems in Australian hospitals. Health Serv Manage Res 2017;30:179-86.

61. Gomes JV, Romão M, Carvalho H. Organisational maturity and project success in healthcare: the mediation of project management. HEALTHINF 2016:359-64.

62. Grossman RL. A framework for evaluating the analytic maturity of an organization. International Journal of Information Management 2018;38:45-51. 
Table S1 Identified studies focused on the use of AI for strategic decision-making in hospitals

\begin{tabular}{|c|c|c|c|c|c|}
\hline Citation & Setting/context & Application & Use & Type of Al & Evaluation \\
\hline \multicolumn{6}{|l|}{ Review articles } \\
\hline Eom \& Kim 2006 (6) & Not specified & $\begin{array}{l}\text { Third literature review of decision support systems (DSS) } \\
\text { from } 1995 \text { to } 2001\end{array}$ & $\begin{array}{l}\text { In healthcare DSSs were operationally focused to improve } \\
\text { patient admission, discharge and billing, collaborative } \\
\text { medical decision-making, scheduling nurses, improve } \\
\text { material management processes, control sexually } \\
\text { transmitted diseeses, and track indicators of mental } \\
\text { health providers' productivity }\end{array}$ & Al decision support systems & $\mathrm{N} / \mathrm{A}$ \\
\hline $\begin{array}{l}\text { Broekhuizen et al., } \\
2015(27)\end{array}$ & $\begin{array}{l}\text { Literature review of SCOPUS and PubMed } \\
\text { from 1960-2013 for multi-criteria decision } \\
\text { analysis (MCDA) to identify models to } \\
\text { address uncertainly for application to } \\
\text { healthcare decision-making }\end{array}$ & $\begin{array}{l}\text { Identified five methods: Bayesian framework, deterministic } \\
\text { sensitivity analysis, probabilistic sensitivity analysis, fuzzy } \\
\text { set theory and gray theory }\end{array}$ & $\begin{array}{l}\text { Identified } 7 \text { papers using MCDA for health policy } \\
\text { decisions. Four studies used deterministic sensitivity } \\
\text { analysis, two used probabilistic sensitivity analysis and } \\
\text { one used fuzzy set theory }\end{array}$ & $\begin{array}{l}\text { Deterministic most appropriate if the criteria weights } \\
\text { are varied as a single value. Gray approach most } \\
\text { appropriate if only lower and upper bounds are used. In } \\
\text { a group decision process where the opinions of several } \\
\text { decision-makers are combined, the probabilistic and } \\
\text { fuzzy set approaches allow distributions }\end{array}$ & N/A \\
\hline Duan et al., 2019 (5) & $\begin{array}{l}\text { Review of papers published in International } \\
\text { Journal of Information Management }\end{array}$ & History and development of $\mathrm{Al}$ & $\begin{array}{l}\text { Identified } 52 \text { substantive papers; mostly used in } \\
\text { manufacturing, health care and legal practice. } 12 \\
\text { research propositions in theory development, technology- } \\
\text { human interface and Al implementation }\end{array}$ & $\begin{array}{l}\text { Greatest Al type was rules-based, with change from } \\
\text { humans identifying rules to machines identifying the } \\
\text { rules }\end{array}$ & $\mathrm{N} / \mathrm{A}$ \\
\hline Shahid et al., 2019 (9) & Scoping review & $\begin{array}{l}\text { Scoping review of ANNs in healthcare organisational } \\
\text { decision-making }\end{array}$ & $\begin{array}{l}18 \% \text { of } 80 \text { articles were classified as organisational } \\
\text { behaviour and included: behaviour and perspectives, } \\
\text { crisis or risk management, clinical and non-Clinical } \\
\text { decision-making, and resource management. Only } 10 \\
\text { studies could be considered as strategic application }\end{array}$ & Supervised data-driven & $\mathrm{N} / \mathrm{A}$ \\
\hline \multicolumn{6}{|l|}{ Descriptive studies } \\
\hline $\begin{array}{l}\text { Hedelin \& Allwood, } \\
2002 \text { (13) }\end{array}$ & $\begin{array}{l}\text { Public and private sector organisations } \\
\text { in Sweden with three public hospital } \\
\text { participants }\end{array}$ & $\begin{array}{l}\text { Interviewed } 41 \text { senior managers on use of information and } \\
\text { communications technology (ICT) for strategic decision- } \\
\text { making }\end{array}$ & $\begin{array}{l}\text { Wanted user friendly systems they could use that } \\
\text { extracted information from various databases into an } \\
\text { analytic database that could complete all statistical } \\
\text { analysis. Needed to obtain trustworthy data more easily } \\
\text { and quickly }\end{array}$ & $\mathrm{N} / \mathrm{A}$ & $\begin{array}{l}\text { N/A. Concerned that it would not be possible to } \\
\text { use ICT to a greater extent in strategic decision- } \\
\text { making without tinappropriate simplification and } \\
\text { standardisation }\end{array}$ \\
\hline Yang et al., 2013 (28) & Two hospitals in Asia & Case studies & $\begin{array}{l}\text { Tracked the decision process to implement wireless vital } \\
\text { sign monitoring systems. Found eight enabling factors, } \\
\text { with issue driven and clinical trigger factors influencing a } \\
\text { stronger organisational mandate, with centrally-led more } \\
\text { connected senior champions and project team members, } \\
\text { vendor alignment with resources shared throughout } \\
\text { the organisation, appeared to influence a better pilot } \\
\text { outcome }\end{array}$ & Data-driven & $\begin{array}{l}\text { N/A. Not strategically focused, as the case } \\
\text { studies explored a local clinical application, but } \\
\text { results may be relevant for A A implementation } \\
\text { for strategic decisions making }\end{array}$ \\
\hline \multicolumn{6}{|l|}{ Application articles } \\
\hline Fala et al., 1995 (36) & $\begin{array}{l}\text { Not specified, but focused on cost and } \\
\text { utilisation reduction in USA health system }\end{array}$ & $\begin{array}{l}\text { Describes four expert systems: INFER, PsychiNFER, } \\
\text { Procedure Necessity, and Alternatives to } \\
\text { Non-Surgical Admissions (ANSA) using a classic knowledge } \\
\text { engineering approach }\end{array}$ & $\begin{array}{l}\text { INFER and PsychINFER help to identify potentially } \\
\text { catastrophic or chronic cases so that they may be } \\
\text { aggressively managed. Procedure Necessity helps } \\
\text { to decide whether a surgical or diagnostic procedure } \\
\text { is necessary on a case-by-case. The systems advise } \\
\text { specialists, who use their own judgement }\end{array}$ & Rule-based system & $\begin{array}{l}\text { Authors suggest, but do not provide analysis } \\
\text { of, greater return on investment in case } \\
\text { management, reductions in inappropriate } \\
\text { referrals, and greater consistency in decision- } \\
\text { making }\end{array}$ \\
\hline $\begin{array}{l}\text { Forgionne and Kohli, } \\
1996(29)\end{array}$ & $\begin{array}{l}\text { Evaluated by students at Johns Hopkins } \\
\text { University, University of Baltimore and health } \\
\text { professionals at Saint Joseph Hospital, USA }\end{array}$ & Hospital Management Support System (HMSS) & $\begin{array}{l}\text { Provides integrated clinical and administrative data to } \\
\text { assist concurrent engineering, which, although focused } \\
\text { on operations, was suggested would help hospitals } \\
\text { achieve their strategic objectives }\end{array}$ & Knowledge-based & $\begin{array}{l}\text { Evaluation with control group using standard } \\
\text { StratPlan DSS and experimental group using } \\
\text { HMSS for a planning exercise, which suggested } \\
\text { HMSS provided greater maturity in decision- } \\
\text { making and better performance }\end{array}$ \\
\hline Abidi, 1999 (30) & Not specified & $\begin{array}{l}\text { Theoretical description of a Strategic Knowledge Services } \\
\text { Info-structure }\end{array}$ & $\begin{array}{l}\text { Gathering information from a variety of existing } \\
\text { healthcare databases to make strategic decisions on } \\
\text { service capacity, costs, policy and planning }\end{array}$ & Knowledge-based & No evaluation \\
\hline $\begin{array}{l}\text { Edmonds \& } \\
\text { O'Connor, } 1999 \text { (34) }\end{array}$ & $\begin{array}{l}\text { Emergency departments in South Eastern } \\
\text { Ontario Health, Sciences Centre, comprising } \\
\text { public hospitals in Kingston, Canada }\end{array}$ & $\begin{array}{l}\text { Discrete-event stochastic computer simulation using MS } \\
\text { Access }\end{array}$ & $\begin{array}{l}\text { Model changes to ED performance (occupancy, } \\
\text { workload, length of stay) by manipulating ED capability, } \\
\text { hours, staffing profile }\end{array}$ & Knowledge-based & $\begin{array}{l}\text { Three scenarios for hospital restructuring were } \\
\text { completed, but there was no evaluation of the } \\
\text { accuracy of the simulation results }\end{array}$ \\
\hline $\begin{array}{l}\text { Moreno et al., } \\
2000(32)\end{array}$ & Not specified-aimed for use by hospitals & Computer simulation using discrete event algorithm & $\begin{array}{l}\text { Track hospital patient flow to enable testing of various } \\
\text { strategies to assist decision-making }\end{array}$ & Expert system & No evaluation \\
\hline $\begin{array}{l}\text { Moreno et al., } \\
2001 \text { (33) }\end{array}$ & Not specified & $\begin{array}{l}\text { Theoretical description of how domain and control } \\
\text { knowledge is included in a knowledge-based system } \\
\text { (KBS) using KAAS to be used for hospital management } \\
\text { monitoring, diagnosis, prediction and design }\end{array}$ & $\begin{array}{l}\text { Possible solutions obtained during the prediction task are } \\
\text { used to build a solution where all management problems } \\
\text { detected in the system can be solved }\end{array}$ & Knowledge-based & No evaluation \\
\hline Ramani, 2004 (31) & $\begin{array}{l}\text { Three general hospitals administered by } \\
\text { Ahmedabad Municipal Corporation (AMC), } \\
\text { India }\end{array}$ & $\begin{array}{l}\text { Describes the performance indicators of a management } \\
\text { information system incorporating data from various parts of } \\
\text { the hospital. Also describes aspects of the implementation } \\
\text { process }\end{array}$ & $\begin{array}{l}\text { Generates estimates of a limited set of hospital } \\
\text { performance indicators }\end{array}$ & Knowledge-based & No evaluation \\
\hline $\begin{array}{l}\text { Mousakhani et al., } \\
2010(37)\end{array}$ & Five hospitals in Iran & $\begin{array}{l}\text { Used fuzzy logic in Analytical Hierarchical Process (AHP) } \\
\text { to compare the published strategic balanced scorecards of } \\
\text { five hospitals }\end{array}$ & $\begin{array}{l}\text { Four scorecard perspectives and } 16 \text { performance } \\
\text { indicators were raked in pairs in relation to the strategic } \\
\text { objective to enable ranking of the hospitals }\end{array}$ & Model-based & No evaluation \\
\hline Aktaş et al., 2007 (38) & $\begin{array}{l}\text { Radiology department of a private hospital } \\
\text { in Turkey }\end{array}$ & Bayesian Belief Network (BBN) & $\begin{array}{l}\text { Provides a picture of current resource utilisation in a } \\
\text { process and identifies potential strategies to improve } \\
\text { resource utilisation }\end{array}$ & Probabilistic reasoning & No evaluation \\
\hline $\begin{array}{l}\text { McClean and Millard, } \\
2007 \text { (40) }\end{array}$ & $\begin{array}{l}\text { UK NHS system comprising hospital, } \\
\text { patient's home, residential home, nursing } \\
\text { home and death with rehabilitation and } \\
\text { prosthetic service models }\end{array}$ & Markov reward model & $\begin{array}{l}\text { Cost the movement of older patients within a healthcare } \\
\text { system. Illustrated that keeping patients longer in } \\
\text { hospital, improving their fitness for discharge can reduce } \\
\text { transfer of patients into secondary care systems and may } \\
\text { both improve hospital performance and reduce costs }\end{array}$ & Probabilistic reasoning & $\begin{array}{l}\text { No evaluation, as authors indicate it is difficult } \\
\text { to get accurate data }\end{array}$ \\
\hline $\begin{array}{l}\text { Fernández \& } \\
\text { Ossowski, } 2008 \text { (35) }\end{array}$ & Not specified & $\begin{array}{l}\text { Describes the development of a Service-Oriented } \\
\text { Multi-Agent System (SOMAS) that uses organisational } \\
\text { information on roles of agents and the interactions among } \\
\text { these agents in the provision of services to model service } \\
\text { coordination }\end{array}$ & $\begin{array}{l}\text { Provides matches of services and service providers to } \\
\text { the defined needs, that is most effective with the use of a } \\
\text { role-based filter }\end{array}$ & Knowledge-based & $\begin{array}{l}\text { Was evaluated against an existing service } \\
\text { matchmaker and the addition of the roles and } \\
\text { interactions in SOMAS was found to outperform } \\
\text { in efficiency and effectiveness of the matches }\end{array}$ \\
\hline $\begin{array}{l}\text { Nunes et al., } \\
2009(41)\end{array}$ & Not provided & $\begin{array}{l}\text { Markov decision process involving patient demand, } \\
\text { treatment patterns and hospital resources }\end{array}$ & Modelling elective hospital admissions by speciality & Probabilistic reasoning & No evaluation \\
\hline $\begin{array}{l}\text { Malliaris \& Pappas, } \\
2011 \text { (44) }\end{array}$ & Hospital foundations in the USA & $\begin{array}{l}\text { ANN with information on campaigns and events obtained } \\
\text { from websites and financial information from non-profit } \\
\text { reporting }\end{array}$ & $\begin{array}{l}\text { Predict the fundraising revenue arising from different } \\
\text { fundraising strategies }\end{array}$ & Supervised data-driven & $\begin{array}{l}\text { Comparison of ANN and multiple regression } \\
\text { model found greater accuracy with ANN }\end{array}$ \\
\hline $\begin{array}{l}\text { Eswaran \& } \\
\text { Logeswaran, } \\
2012(43)\end{array}$ & $\begin{array}{l}\text { Population health data, such as birth rate, } \\
\text { mortality from tuberculosis for Indonesia }\end{array}$ & ANN in combination with linear regression & $\begin{array}{l}\text { Predict the three population health indicators using the } \\
\text { model and compared to actual and analyse the effect of } \\
\text { management decisions }\end{array}$ & Supervised data-driven & $\begin{array}{l}\text { Predicted indicator values were close to actual } \\
\text { values }\end{array}$ \\
\hline $\begin{array}{l}\text { Cohan et al., } \\
2017(49)\end{array}$ & Unidentified hospital data from USA & Convolutional and recurrent neural networks & More efficiently capture narratives of patient harm & Supervised data-driven & $\begin{array}{l}\text { Performed better than existing methods in } \\
\text { identifying patient harm using two datasets with } \\
76,752 \text { patient incident reports }\end{array}$ \\
\hline Tafti et al., 2017 (50) & $\begin{array}{l}\text { Structured and unstructured text data from } \\
\text { scientific publications and social medias on } \\
\text { the Internet }\end{array}$ & $\begin{array}{l}\text { Machine learning was used to collect evidence of the } \\
\text { impact of adverse medical drug events associated with } 28 \\
\text { prescribed drugs }\end{array}$ & $\begin{array}{l}\text { Efficiently summarise text-based clinical findings in } \\
\text { extremely large databases }\end{array}$ & Supervised data-driven & $\begin{array}{l}\text { Outperformed physical collection by trained } \\
\text { researchers }\end{array}$ \\
\hline Wang et al., 2018 (51) & Barnes-Jewish Hospital, USA & $\begin{array}{l}\text { Cost sensitive (convolutional) deep neural network } \\
\text { algorithm (CSDNN) }\end{array}$ & Predict hospital readmissions & Supervised data-driven & $\begin{array}{l}\text { Algorithm was evaluated using existing datasets } \\
\text { and performed better than baseline on two } \\
\text { indicators }\end{array}$ \\
\hline $\begin{array}{l}\text { Erdoğan et al., } \\
2019 \text { (42) }\end{array}$ & UK National Health Service Trust & $\begin{array}{l}\text { Excel-based Decision Support System for Facility Location } \\
\text { Problems using a Tabu Search algorithm and linking to a } \\
\text { Geographic Information System }\end{array}$ & $\begin{array}{l}\text { Evaluate current maternity services model and provide } \\
\text { analysis to determine opening, closing, relocating } \\
\text { maternity services }\end{array}$ & Data-driven & $\begin{array}{l}\text { While recommendations were accepted for } \\
\text { implementation, this has not been evaluated }\end{array}$ \\
\hline $\begin{array}{l}\text { Sun \& Medaglia, } \\
2019 \text { (39) }\end{array}$ & $\begin{array}{l}\text { Zhejiang Provincial Hospital of Traditional } \\
\text { Chinese Medicine in China }\end{array}$ & $\begin{array}{l}\text { Identified challenges to implementation of Al to design } \\
\text { individual treatment plans }\end{array}$ & $\begin{array}{l}\text { Poses natural language questions to design a treatment } \\
\text { plan }\end{array}$ & Probabilistic evidence-based & $\begin{array}{l}\text { Study found social, economic, ethical, political, } \\
\text { data, technological and of most relevance } \\
\text { organisational and managerial challenges. } \\
\text { These include lack of Al strategy, tension } \\
\text { between data integration, and interests of } \\
\text { individual organisations in keeping the data, } \\
\text { lack of competent workforce, fears of workforce } \\
\text { substitution and lack of trust of Al decisions }\end{array}$ \\
\hline
\end{tabular}

